\title{
Pengamanan Data Penggajian Menggunakan Vigenere Chiper Pada Mom's Kitchen Medan
}

\author{
Yopi Hendro Syahputra1, Azlan², Lidya Acecia Girsang ${ }^{3}$ \\ ${ }^{1}$ Teknik Komputer, STMIK Triguna Dharma \\ ${ }^{2,3}$ Sistem Informasi, STMIK Triguna Dharma
}

\begin{tabular}{|c|c|}
\hline Article Info & בABSTRACT \\
\hline $\begin{array}{l}\text { Article history: } \\
\text { Received Jan 02 } \\
\text { th }, 2022 \\
\text { Revised Jan } 15^{\text {th }}, 2022 \\
\text { Accepted Jan } 26^{\text {th }}, 2022\end{array}$ & $\begin{array}{l}\text { Data penggajian merupakan hal yang sensitif di kalangan } \\
\text { pekerja/staf/karyawan. Kebocoran data penggajian terkadang bisa } \\
\text { menimbulkan permasalahan di internal perusahaan. Salah satu solusi yang } \\
\text { bisa diterapkan dalam mengamankan data penggajian adalah menggunakan } \\
\text { teknik Kriptografi. Algoritma Vigenere Chiper bisa dipakai untuk } \\
\text { mengamankan data penggajian. Penelitian ini dilakukan di toko Mom's }\end{array}$ \\
\hline $\begin{array}{l}\text { Keyword: } \\
\text { Kriptografi } \\
\text { Mom's Kitchen } \\
\text { Penggajian } \\
\text { Vigenere Chiper }\end{array}$ & $\begin{array}{l}\text { Kitchen Medan. Hasil dari penelitian ini dapat membantu pihak Mom's } \\
\text { Kitchen dalam mengamankan data penggajian, dengan cara menyandikan } \\
\text { data tersebut sebelum disimpan didalam database. Setelah } \\
\text { pengimplementasian sistem di Mom's Kitchen, tingkat kekhawatiran terhadap } \\
\text { kebocoran data gaji telah berkurang. Walaupun algoritma vigenere chipher } \\
\text { tergolong algoritma klasik, dinilai masih cukup aman untuk digunakan dalam } \\
\text { mengamankan data penggajian di Mom's Kitchen. }\end{array}$ \\
\hline
\end{tabular}

Copyright $\odot 2022$ STMIK Triguna Dharma. All rights reserved.

\begin{abstract}
Corresponding Author: First Author
Nama : Yopi Hendro Syahputra

Program Studi : Teknik Komputer

Afiliasi : STMIK Triguna Dharma

Email : yopihendro@gmail.com
\end{abstract}

\section{PENDAHULUAN}

Data merupakan komponen utama dari sistem informasi perusahaan karena proses pengambilan keputusan berasal dari data. Oleh karena itu sudah sewajarnya jika pengolahan data dipandang sebagai kebutuhan primer oleh perusahaan. Pengolahan data yang buruk dapat mengakibatkan tidak tersedianya data penting yang digunakan untuk menghasilkan informasi yang diperlukan dalam pengambilan keputusan [1]. Data memiliki fungsi yang sangat penting bagi kinerja perusahaan. Perusahaan membutuhkan penyusunan data yang baik agar dapat digunakan dalam pengambilan keputusan, misalnya saja untuk dapat mengetahui tingkat kemakmuran karyawan, perusahaan dapat menggunakan data gaji bulanan dan data tanggungan setiap karyawan. Untuk menghindari terjadinya penyalahgunaan dan manipulasi terhadap data tersebut, maka diperlukan suatu upaya untuk mengamankan data.

Kondisi tersebut membuat peruhaaan-perusahaan berupaya membangun suatu sistem yang mampu mengamankan data internal yang dimilikinya. Salah satu perusahaan yang berupaya membangun keamanan datanya ialah toko Mom's Kitchen. Mom's Kitchen merupakan toko yang menjual berbagai makanan dan minuman. Dalam pencatatan data gaji karyawannya masih dilakukan secara manual, sehingga sangat memungkinkan bagi pihak lain untuk dapat menyalahgunakan data tersebut. Berdasarkan hal tersebut, disimpulkan bahwa perlu adanya sebuah sistem yang mampu mengolah dan mengamankan data gaji karyawan.

Penelitian ini menjelaskan bagaimana pemanfaatan kriptografi dalam mengamankan data gaji karyawan. Menggunakan kriptografi adalah salah satu cara untuk mencegah kebocoran data yang bersifat rahasia [2]. Dalam beberapa literatur dijelaskan bahwa kriptografi dapat memecahkan permasalahan seperti mengamankan data penjualan [3], mengamankan aplikasi tes masuk karyawan [4], mengamankan data gambar [5] dan juga mengamankan data barang [6]. Dari jurnal-jurnal tersebut menjelaskan bahwasanya kriptografi dapat menyelesaikan permasalahan yang bersifat pengamanan data. Dalam mengamankankan data, kriptografi memiliki beberapa metode, salah satunya ialah metode Vigenere Cipher. 
Vigenere Cipher adalah salah satu algoritma kriptografi klasik yang diperkenalkan pada abad 16 atau kira-kira pada tahun 1986. Cara kerja dari Vigenere Cipher ini mirip dengan Caesar Cipher, yaitu mengenkripsi plainteks pada pesan dengan cara menggeser huruf pada pesan tersebut sejauh nilai kunci pada deret alphabet [7].

Toko Mom's Kitchen membutuhkan sebuah sistem pengamanan data gaji karyawan berbasis desktop yang teknik pengamanannya menerapkan algoritma Vigenere Cipher. Dengan adanya sistem pengamanan data gaji, data gaji karyawan dapat disimpan dengan aman tanpa adanya kekhawatiran penyalahgunaan data oleh orang yang tidak bertanggungjawab.

\section{METODE PENELITIAN}

\subsection{Metodologi Penelitian}

Menjelaskan kronologi penelitian, termasuk desain penelitian, prosedur penelitian (dalam bentuk algoritma, Dalam penelitian ini untuk mendapatkan data dilakukan beberapa cara yaitu sebagai berikut :

1. Data Collecting. Dalam pengumpulan data dilakukan observasi dan wawancara. Dalam observasi melakukan tinjauan langsung ke Mom's Kitchen Medan. Hasil dari wawancara terhadap petugas yang menangani data gaji karyawan, dapat dilihat pada tabel 1 sebagai berikut :

Tabel 1. Data Gaji Karyawan Mom's Kitchen Medan

\begin{tabular}{lllll}
\hline Nama & Gaji Pokok & Lembur & Terlambat & Gaji Bersih \\
\hline LASMIAN & 1.350 .000 & - & - & 1.350 .000 \\
RUMINCE & 1.750 .000 & - & - & 1.750 .000 \\
LENA & 1.850 .000 & - & - & 1.850 .000 \\
FEBRI & 2.750 .000 & - & - & 2.750 .000 \\
BUNGA & 1.850 .000 & - & - & 1.850 .000 \\
MELLY & 1.750 .000 & - & - & 1.750 .000 \\
EMIL & 1.300 .000 & - & - & 1.300 .000 \\
LINA & 3.000 .000 & - & - & 3.000 .000 \\
\hline
\end{tabular}

2. Studi Literatur. Penelitian ini banyak menggunakan jurnal-jurnal baik jurnal nasional maupun buku sebagai sumber referensi.

\subsection{Metode Perancangan Sistem}

Dalam merancang sistem metode yang digunakan adalah metode waterfall. Berikut ini adalah fase yang dilakukan dalam metode waterfall :

1. Analisis Kebutuhan Sistem

Menganalisis hal-hal yang diperlukan dalam sistem yang akan dirancang.

2. Desain Sistem

Dalam mendesain/memodelkan sistem digunakan Unified Modelling Language, membuat desain interface dan flowchart.

3. Membangun Sistem

Fase ini melakukan pengkodingan untuk membangun sistem sesuai desain sistem. Pengkodingan menggunakan bahasa pemrograman berbasis desktop.

4. Uji Coba Sistem

Fase ini melakukan pengetesan terhadap sistem yang sudah dibangun khususnya keakuratannya dalam melakukan enkripsi dan dekripsi.

5. Implementasi Sistem

Fase akhir ini adalah fase dimana pemanfaatan aplikasi oleh stakeholder yang akan menggunakan sistem ini.

\section{ANALISA DAN HASIL}

Berikut langkah-langkah pemecahan masalah dalam mengamankan data gaji karyawan menggunakan metode Vigenere Cipher :

1. Enkripsi Data Gaji Karyawan

Jika diketahui plaintext adalah LASMIAN yang apabila dikonversi ke bilangan desimal menjadi 766583 77736578 dan kunci yang digunakan misalnya LIDIA yang apabila dikonversi ke bilangan desimal menjadi 76736873 65, dengan menerapkan rumus $\mathrm{Ci}=(\mathrm{Pi}+\mathrm{Ki}) \bmod 256$, maka proses enkripsinya sebagai berikut :

$\begin{array}{llllllll}\text { Plaintext } & 76 & 65 & 83 & 77 & 73 & 65 & 78\end{array}$ 


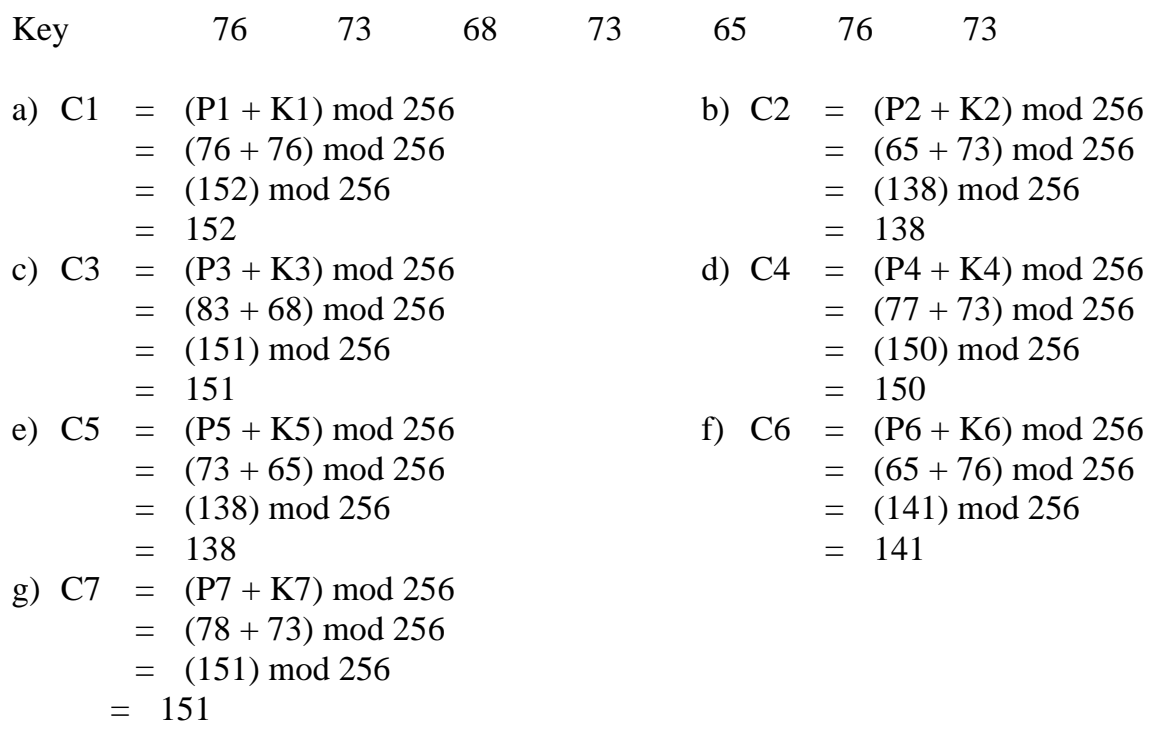

Dari langkah-langkah diatas, didapatkan hasil enkripsi 152138151150138141151 yang apabila dikonversi kedalam bentuk hexadecimal menjadi 98 8A 9796 8A. Proses enkripsi data gaji karyawan dapat dilihat melalui gambar 1 flowchart sebagai berikut :

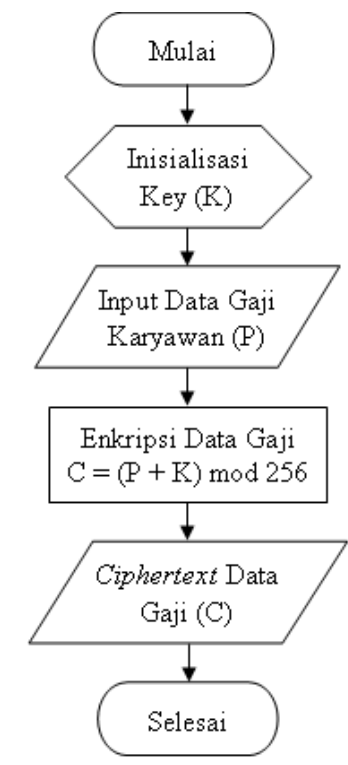

Gambar 1. Algoritma Enkripsi Data Gaji Karyawan

2. Dekripsi Data Gaji Karyawan

Untuk proses dekripsinya dapat dilakukan menggunakan rumus $\mathrm{Pi}=(\mathrm{Ci}-\mathrm{Ki}) \bmod 256$.

Ciphertext: $152138151 \quad 150138141 \quad 151$

Langkah-langkah dekripsi Ciphertext menjadi Plaintext sebagai berikut :
a) $\mathrm{P} 1=(\mathrm{C} 1-\mathrm{K} 1) \bmod 256$
b) $\mathrm{P} 2=(\mathrm{C} 2-\mathrm{K} 2) \bmod 256$
$=(152-76) \bmod 256$
$=(138-73) \bmod 256$
$=(76) \bmod 256$
$=76$
$=(138) \bmod 256$
$=65$
c) $\mathrm{P} 3=(\mathrm{C} 3-\mathrm{K} 3) \bmod 256$
$=(151-68) \bmod 256$
d) $\mathrm{P} 4=(\mathrm{C} 4-\mathrm{K} 4) \bmod 256$
$=(83) \bmod 256$
$=83$
$=(150-73) \bmod 256$
$=(77) \bmod 256$
$=77$
e) $\mathrm{P} 5=(\mathrm{C} 5-\mathrm{K} 5) \bmod 256$
$=(138-65) \bmod 256$
$=(73) \bmod 256$
f) $\mathrm{P} 6=(\mathrm{C} 6-\mathrm{K} 6) \bmod 256$
$=(141-76) \bmod 256$
$=(65) \bmod 256$ 
$=73$

$$
=65
$$

g) $\mathrm{P} 7=(\mathrm{C} 7-\mathrm{K} 7) \bmod 256$

$=(151-73) \bmod 256$

$=(78) \bmod 256=78$

Dari langkah-langkah diatas, didapatkan hasil dekripsi 76658377736578 yang apabila dikonversi kedalam bentuk huruf menjadi LASMIAN. Proses dekripsi data gaji karyawan dapat dilihat melalui gambar 2 flowchart berikut :

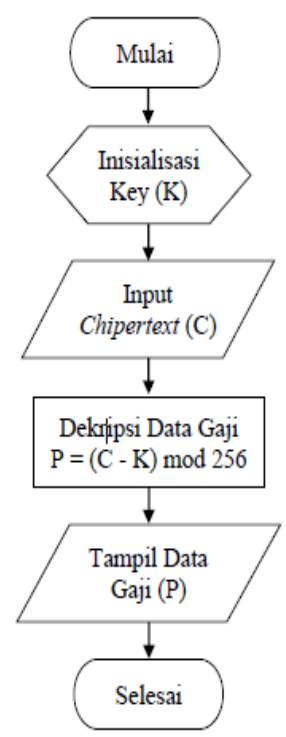

Gambar 2. Algoritma Dekripsi Data Gaji Karyawan

Hasil dari pembangunan sistem pengamanan data gaji karyawan sebagai berikut :

1. Form Login

Form login pada gambar 3 merupakan form yang digunakan admin untuk masuk kedalam aplikasi pengamanan data gaji karyawan.

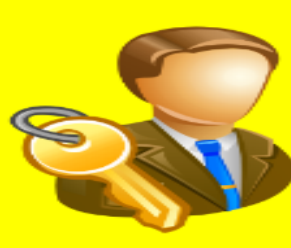

Username

lidia

Password

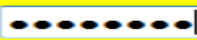

\section{Login}

Cancel

2. Form Menu Utama

Form menu utama pada gambar 4 adalah form yang akan muncul setelah admin berhasil login kedalam aplikasi pengamanan data gaji karyawan.

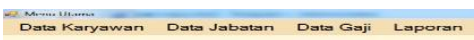

Gambar 4. Form Menu Utama 
3. Form Data Karyawan

Form data karyawan pada gambar 5 adalah form yang digunakan admin untuk menginput, mengedit dan menghapus data karyawan.

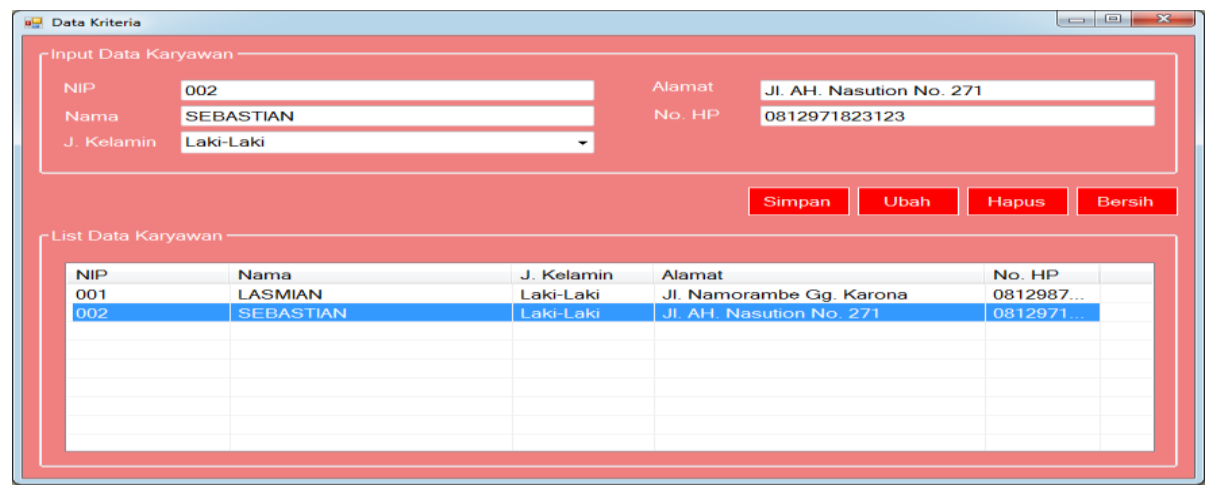

Gambar 5. Form Data Karyawan

4. Form Data Jabatan

Form data jabatan pada gambar 6 adalah form yang akan digunakan admin untuk menginput, mengedit dan menghapus data jabatan.

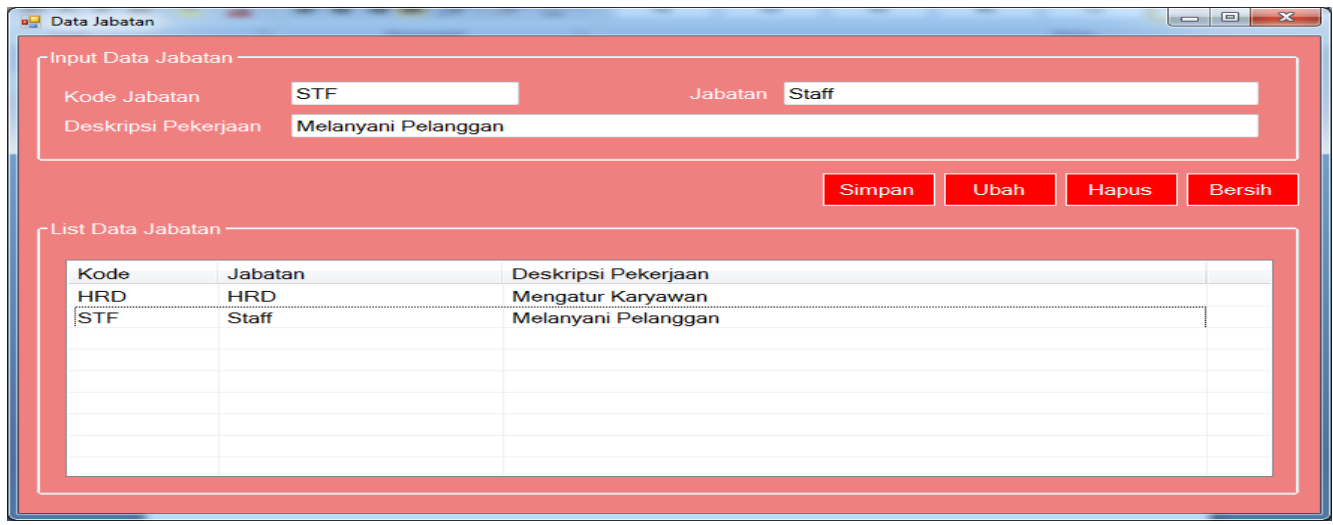

Gambar 6. Form Data Jabatan

\section{Form Data Gaji}

Form data gaji pada gambar 7 adalah form yang digunakan admin untuk menginput, mengedit dan menghapus data gaji.

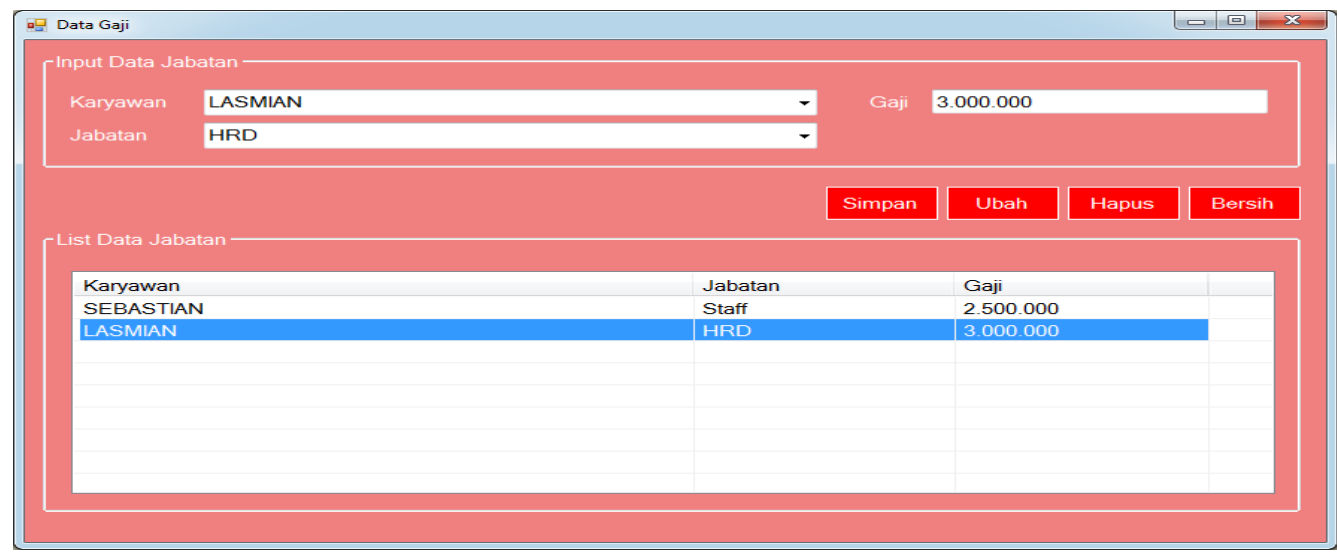

Gambar 7. Form Data Gaji 


\section{KESIMPULAN}

Kesimpulan yang dapat diambil dari penelitian ini adalah sebagai berikut :

1. Setelah pengimplementasian sistem di Mom's Kitchen, tingkat kekhawatiran terhadap kebocoran data gaji telah berkurang.

2. Walaupun algoritma vigenere chipher tergolong algoritma klasik, dinilai masih cukup aman untuk digunakan dalam mengamankan data penggajian di Mom's Kitchen.

\section{REFERENSI}

[1] Doro Edi and Stevalin Betshani, "Analisis Data dengan Menggunakan," vol. 5, pp. 71-85, 2009.

[2] Mohamad Natsir, "Pengembangan Prototype Sistem Kriptografi Untuk Enkripsi Dan Dekripsi Data Office Menggunakan Metode Blowfish Dengan Bahasa Pemrograman Java," vol. 6, pp. 87-105, 2017.

[3] Susanto and Anto, Tri Susilo Andri, "Penerapan Algoritma Asimetris Rsa Untuk Keamanan Data Pada Aplikasi Penjualan CV. Sinergi Computer Lubuklinggau Berbasis Web," vol. 9, pp. 1043-1052, 2018.

[4] Geri Grehasen and Sri Mulyati, "Pengamanan Database Pada Aplikasi Test Masuk Karyawan Baru Berbasis Web Menggunakan Algoritma Kriptografi AES-128 Dan RC4," vol. 14, pp. 52-60, 2017.

[5] Wandira, Simatupang Ayu, "Aplikasi Pengamanan Data Gambar Dengan Menerapkan Algoritma Vigenere Chiper," vol. 2, pp. 66-72, 2017.

[6] Murni Marbun, "Implementasi Sistem Pengamanan Data Barang Pada PT. Matahari Putra Prima, Tbk," vol. 18, pp. 1-10, 2015.

[7] Muhammad Dedi Irawan, "Implementasi Kriptografi Vigenere Cipher Dengan PHP," vol. 1, pp. 11-21, 2017.

\section{BIBLIOGRAFI PENULIS}

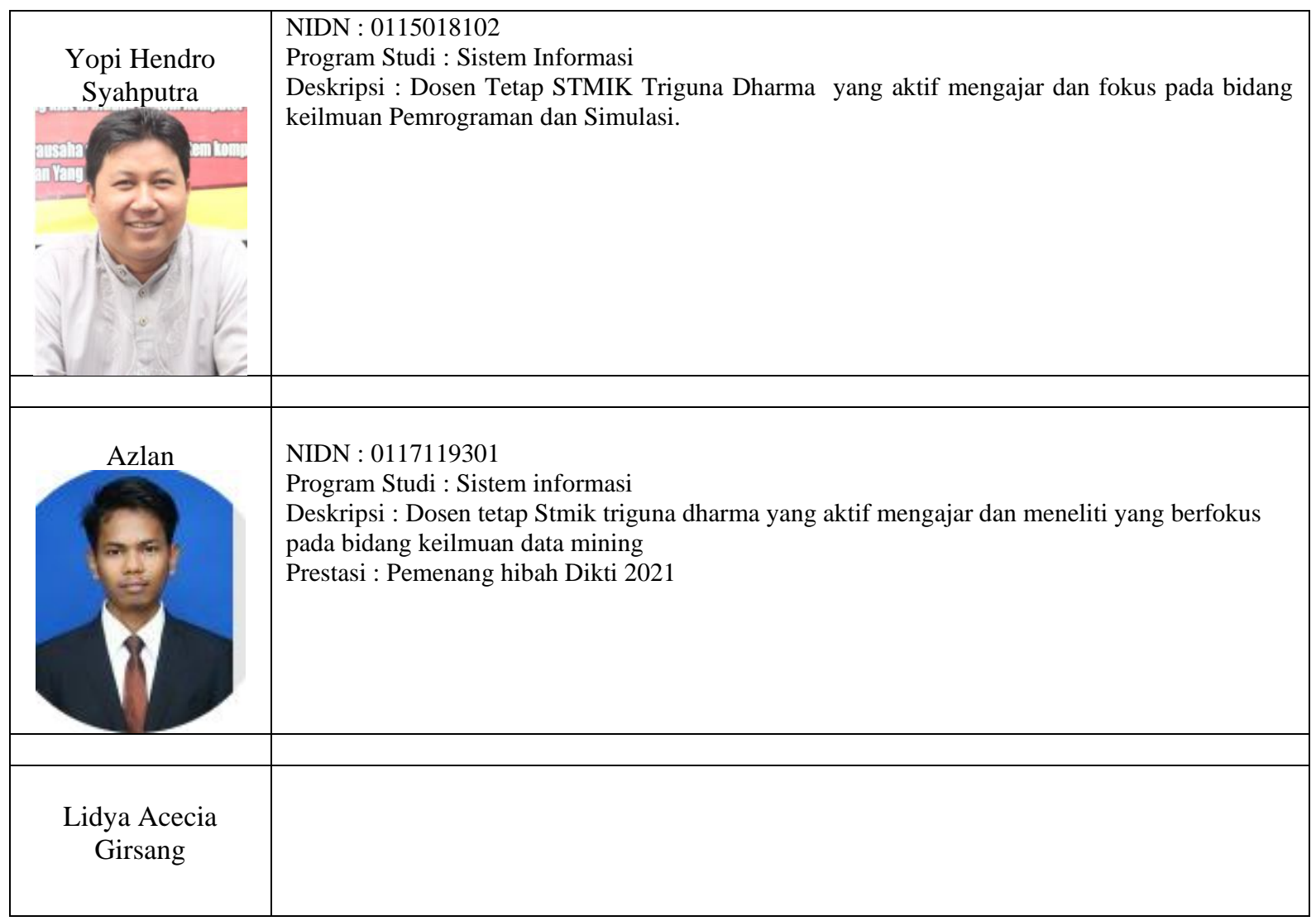

